\title{
Review of The Near-Death Experience: A Reader
}

To the Editor:

Would you criticize a giraffe for not being an elephant? Or an eagle for not being a sparrow? Jenny Wade's review in the Spring 1999 issue of the Journal of our book, The Near-Near-Death Experience: A Reader, edited by Lee Bailey and Jenny Yates (1996) suffered from the logical flaw called "the straw person." In this fallacy, one sets up a misconception and attacks it, rather than analyzing the reality at hand. Those of us working in areas such as near-death experiences (NDEs) must be very careful not to fall unintentionally into logical pitfalls, but Wade regrettably fell into this trap. 
She set up her straw person by asserting that "this anthology is not intended as a textbook." I do not know how she can read the intentions of the authors, but that was part of our purpose. We sought to reach an audience of college students and thoughtful readers with a willingness to reflect both sympathetically and critically to NDEs. We tried to cross the divide between (a) the broadly popular trade books that too often neglect critical analysis and (b) the research literature that focuses on a specialized professional readership. We intentionally edited a bridging book, not the book that our reviewer expected. So she naturally reacted critically to a type of book and an audience that she did not envision.

As college teachers we aimed at an undergraduate audience, and college graduates, whereas perhaps Wade wanted us to serve a graduate audience engaging in the rigors of postgraduate thought. As I teach using the book, I find it a perfectly appropriate introduction to NDEs for undergraduates. It stretches them in both directions: the soulful mystery of the experience itself on one side, and the scholarly scepticism and careful analysis on the other side. So we assumed it would appeal to a broad, educated audience willing to be stretched in the same way. This is also why we chose some NDEs of well-known people, rather than only the newly found ones prized by researchers (although I have my file of those too).

We offered a generally accessible methodological presentation in the introduction, explaining the biological, psychological, philosophical, and religious methods of analyzing NDEs, in order to introduce new readers to the field. Of course some of its points could be appropriate for current researchers, as well. For example, I wish more researchers would take responsibility for the philosophical issues underlying their methodologies, such as the difference between the deductive (death is a one-way trip) and the inductive (lack of vital life signs) definitions of death, that Yates contributed to our book. We reached out to introductory readers willing to begin exploring research issues, with minimal fine-tuning of the methodological disputes, because the research literature was already doing that.

In order to serve this broad audience, we purposely chose to present the classical positions of major NDE scholars, in order to provide newcomers with an introduction to the field, rather than present their latest views, which are available in the scholarly literature, and rapidly changing. So for the reviewer to write that she wishes we had edited a more current research-oriented book is indulging in the straw person fallacy, and not seeing what is there. I would certainly welcome the kind 
of book that Wade wishes for; perhaps she is the one to do it, rather than criticize others for not doing it.

Contrary to our review's claim, our book did present some barely known NDE cases, such as Mellen-Thomas Benedict's, Peter Sellers' and Eddie Rickenbacker's. Almost half the book's chapters were new essays by thinkers such as Yates, Robert Kastenbaum, Karl Jansen, David Lorimer, and Judith Cressy, for example, plus my "No-Thingness" article.

Our publisher tells us that we have had inquiries from abroad about translating the book, and that it is currently being considered by a major book club. If we can bridge a gap by introducing NDEs in a thoughtful way to a broad audience, we will be content, and will look forward to a research-oriented books by other authors.

\section{References}

Bailey, L. W., \& Yates, J. (Eds.). (1996). The near-death experience: A reader. New York, NY: Routledge.

Wade, J. (1999). [Review of The near-death experience: A reader]. Journal of Near-Death Studies, 17, 211-214.

Lee W. Bailey, Ph.D.

Department of Philosophy and Religion Ithaca College Ithaca, NY 14850 